\title{
Spatiotemporal patterns of drought, its impact on crop production and the economy in South Asia
}

\author{
Alnail Mohmmed ${ }^{1}$, Xiangzheng Deng ${ }^{1}$, Martin Kabenge ${ }^{2}$, Zhihui Li $^{1}$, and Dauglas Juma ${ }^{3}$ \\ ${ }^{1}$ Institute of Geographic Sciences and Natural Resources Research CAS \\ ${ }^{2}$ Tongji University \\ ${ }^{3}$ Macquarie University
}

May 19, 2020

\begin{abstract}
Drought has vastly impacted agriculture all over the globe. However it's impact on crop production: degree and extent is poorly characterized. As the occurrence of more extreme droughts is likely to increase under climate change, understanding the vulnerability of crop production to droughts is a crucial to evaluate and determine the size of the losses. In this study, we used drought events in the South Asia region during the time period 2003-2018, to compare various indices developed for the study of drought phenomena. Three indices namely: the precipitation condition index (PCI), vegetation cover index (VCI) and temperature condition index (TCI) depend on remote sensing data were assimilated to produce an integrated drought severity index (IDSI) to estimate drought conditions. We also correlated the IDSI anomaly with the yield anomaly in the region. The results showed that IDSI has a good correlation with yield anomaly. The study also investigated the influence of drought on area harvested (ha) production (hg/ha) and yield (tons). Economic losses were assessed using the empirical relations between crop yields, IDSI, monthly precipitation, and annual precipitation. The results showed agriculture GDP (AGDP) has a statistically significant correlation ( $\mathrm{p}$-value $<0.01$ ) with economic loss and the correlation coefficient R2 registered 0.32, $0.82,0.84,0.51$ 0.79 and 0.81 in Afghanistan, Pakistan, India, Bhutan, Nepal and Bangladesh respectively. The results of this study offer scientific support for decision-making targeted towards disaster mitigation and adaptation under climate change by identifying the regions in which drought risk control and management.
\end{abstract}

\begin{abstract}
Drought has vastly impacted agriculture all over the globe. However it's impact on crop production: degree and extent is poorly characterized. As the occurrence of more extreme droughts is likely to increase under climate change, understanding the vulnerability of crop production to droughts is a crucial to evaluate and determine the size of the losses. In this study, we used drought events in the South Asia region during the time period 2003-2018, to compare various indices developed for the study of drought phenomena. Three indices namely: the precipitation condition index (PCI), vegetation cover index (VCI) and temperature condition index (TCI) depend on remote sensing data were assimilated to produce an integrated drought severity index (IDSI) to estimate drought conditions. We also correlated the IDSI anomaly with the yield anomaly in the region. The results showed that IDSI has a good correlation with yield anomaly. The study also investigated the influence of drought on area harvested (ha) production (hg/ha) and yield (tons). Economic losses were assessed using the empirical relations between crop yields, IDSI, monthly precipitation, and annual precipitation. The results showed agriculture GDP (AGDP) has a statistically significant correlation (p-value $<0.01$ ) with economic loss and the correlation coefficient $\mathrm{R}^{2}$ registered 0.32, 0.82, 0.84, 0.510 .79 and 0.81 in Afghanistan, Pakistan, India, Bhutan, Nepal and Bangladesh respectively. The results of this study offer scientific support for decision-making targeted towards disaster mitigation and adaptation under climate change by identifying the regions in which drought risk control and management.
\end{abstract}


Keywords; Drought; Vegetation Cover Index (VCI); Integrated Drought Severity Index (IDSI); Agriculture GDP (AGDP)

\section{Introduction}

Drought is a devastating natural phenomenon that has a large impact on agricultural, environmental and socio-economic conditions of the community (Kim, Iizumi, \& Nishimori, 2019; Matewos, 2019). The concept of drought varies among regions of differing climates and resource base (Gao et al., 2018). In general, drought presents a perception of water shortage resulting from low precipitation (Zhang, Jiao, Zhang, Huang, \& Tong, 2017), high evapotranspiration, and over-exploitation of water resources or a mixing of these parameters (Vicente-Serrano, Beguería, \& López-Moreno, 2009). Drought is practically defined both conceptually and operationally (Gao et al., 2018; Rajsekhar, Singh, \& Mishra, 2015). The conceptual definition of drought is essential to create early warning drought policy depending on science-driven assessments, and the operational definitions help to define the beginning, severity and ending of droughts, this comprehensive description assists policy makers, resource planners and other people in realizing and make preparations for drought consequences.

Extreme climatic events like drought globally pose an eminent threat to food security by causing partial or whole damage to regional crop production (Formetta \& Feyen, 2019; Lesk, Rowhani, \& Ramankutty, 2016). Agriculture is the biggest consumer of water and therefore, the most sensitive to drought. Moisture deficit often causes decrease of crops production. As a result the incidence of drought for the duration of the core rainy season has a more significant impact on a country's food production. Its impacts are gradual, therefore it becomes complicated to figure out the beginning and end of a drought occurrence and its associated influence (Stagge, Kohn, Tallaksen, \& Stahl, 2015). Drought impacts have contributed to substantial threats to society, the environment and those sectors dependent on rainfall and water resources (Kellogg, 2019; Mohmmed et al., 2018; Seidl et al., 2017). For instance, agricultural drought produces a huge damage that could span many economic sectors. Among the sectors, agriculture is the main economic sector affected by drought, and particularly, short term agricultural drought at the critical growth periods has severe effects on agriculture (Yu et al., 2018).

Due to the extreme losses in food production and spikes in food prices, droughts have got widespread attention (Esper et al., 2017; Kim et al., 2019). Based on historical studies, Lesk et al. (2016) and Renard and Tilman (2019) stated that droughts decreased worldwide crop production by $10 \%$ from 1964 to 2007. This situation will be exacerbated by climate change which is predicted to cause more persistent and more extensive droughts in the coming years (McDowell et al., 2018)

In the US, the mean annual agricultural production loss inflicted by drought is estimated between $\$ 6$ 8 billion (Ahmadi, Ahmadalipour, Tootle, \& Moradkhani, 2019). Also, it has been revealed that drought loss in Europe in the course of the previous thirty years has exceeded developed countries are significantly impacted by the economic effects of drought, it also has a social effect on the food limited developing countries with great dependency on agriculture (Bayissa et al., 2019). For example, it was assessed that drought caused an estimated loss of US $\$ 12.1$ billion across the whole Kenyan economy between 2008 and 2011, accounting for a reduction in GDP of $2.8 \%$ per year in that period. Countries with small economies are extremely susceptible to catastrophic damage induced by drought and its influences may possibly have sustained impacts on the economy of a country (Cenacchi, 2014). Hagenlocher et al. (2019) revealed that drought risk is clearly primarily based on rural vulnerability and poverty and that "rural poverty is both a lead to and a result of drought risk". As indicated by FAO (2017) droughts constitute a significant stumbling block to accomplishing the Sustainable Development Goals (SDGs) of the United Nations (UN), which aim at among others, ending hunger and achieving food security by 2030, while also promoting sustainable agriculture (Clark (Clark \& Wu, 2016)a. Hence, more regional and sub-regional studies are necessary.

In South Asia, the severe drought that occurred between 1998 and 2001 influenced more than 6000000 people (Agrawala, Barlow, Cullen, \& Lyon, 2001; Ali, Henchiri, Yao, \& Zhang, 2019). It has been noted that the vegetation in South Asia heavily relies on the water availability in the region (Ali (Ali et al., 2019; Cenacchi, 
2014; Gouveia, Trigo, Beguería, \& Vicente-Serrano, 2017). Therefore, to find out the effect of drought on vegetation is a complex issue due to different vegetation types having varying resistance to drought. Moreover, drought impacts under various vegetation species can be significant in evaluating several drought conditions, like drought severity and prevailing time-scales (Gao et al., 2018; Liu et al., 2019). Therefore, understanding the degree, extent and timing of drought-induced damage is crucial.

Several studies have utilized image data of remote-sensing to investigate drought and its effect on vegetation (Anderson et al., 2016; Mohmmed et al., 2018; NOURELDEEN, Kebiao, MOHMMED, Zijin, \& Yanying, 2020; Parsons, Rey, Tanguy, \& Holman, 2019; Sánchez, González-Zamora, Martínez-Fernández, Piles, \& Pablos, 2018). The accessibility of remote-sensing data with broader spatial exposure has aided researchers to identify the spatiotemporal dynamics of drought and its relationship to vegetation dynamics and crop yield (Giannini, Biasutti, \& Verstraete, 2008; Klönne, 2012). Regardless of these advancements, further work is needed to develop the integration and access to accurate and appropriate monitoring and predictive implements to support governmental and non-governmental decision makers, so as to effectively prepare for and appropriately respond to drought and food security issues. Technological advances such as satellite observations, computing resources and communication technologies incorporate with better use of accessible drought monitoring tools as well as increase our capability to more efficiently manage water and other shared natural resources during drought disasters. Therefore we need to improve combination of drought monitoring information available to advance proactive drought and food insecurity risk management strategies within the region. There is a need for a paradigm move from crisis to risk management, which is essential for enhanced food security. An effective approach of risk management policy involves that the best available information from effective and ideal drought monitoring techniques for the region be mutually considered to provide objective information for near real-time food security assessments.

The objectives of this study are to: 1) integrate precipitation, vegetation and land surface temperature indices to investigate drought dynamics over the South Asia region. 2) Establish the impact of drought on the yield of Barley, Maize, Millet, Rice and Wheat. 3) Investigate economic losses in crop production as a result of drought conditions. Also, we examined the relation between economic losses and agriculture gross domestic product (AGDP). The results of this study can help identify which crops in South Asia are more vulnerable to drought and have a more significant impact on economic loss. This will aid policymakers in formulating solutions for drought resilience in the area.

\section{Materials and methods}

\subsection{Study area}

The study area includes six countries in South Asia, namely: Afghanistan, Bangladesh, Bhutan, India, Nepal and Pakistan, which are located between $34^{\circ} 22^{\prime}-38 \operatorname{deg} 23^{\prime}$ N, 114deg09'-122deg43' E (see Figure. 1). The region encompasses a total land area of around 5.2 million $\mathrm{km}^{2}$ and is comprised of various climatic zones such as arid areas, temperate regions, tropical and sub-tropical regions.

Over the past 3 decades, the overall GDP of the region has increased due to agricultural growth and development spurred by the green revolution programme. However, the region has a more significant number of hunger and poor people, around two thirds of these are living in rural areas (Asim (Asim \& Nawaz, 2018; Dizon, Josephson, \& Raju, 2019; Paciorek, Stevens, Finucane, Ezzati, \& Nutrition Impact Model Study, 2013). More than one-quarter of the population in the developing world lives in the South Asia region. Almost 150 million households categorized as agriculture dependents. The mixture of large population and inadequate land area (514 million hectare), means that the rural population density in the developing world is highest in South Asia - at 1.89 persons/ha (Kotharkar, Ramesh, \& Bagade, 2018). The agricultural sector has generated the extras that have reinforced the growth and development of other sectors of the economy. 


\subsection{Data and processing}

\subsubsection{Precipitation condition index (PCI)}

The monthly Climate Hazards Group Infrared Precipitation with Stations (CHIRPS) precipitation dataset was obtained from https://earlywarning.usgs.gov, with a spatial resolution of gridded 0.05deg, and was used in this study to produce precipitation-linked drought conditions. We resampled the data to keep the consistency of spatial resolution. The precipitation condition index( PCI) is performed to assess the precipitation differences and drought conditions (Jiao, Wang, Novick, \& Chang, 2019), which is calculated as:

$$
\mathrm{PCI}=\left(P_{i, j}-P_{\operatorname{minj}}\right) /\left(P_{\max , j}-P_{\min , j}\right) \times 100
$$

Where $\mathrm{I}=1,2,3 \ldots, \mathrm{n}$ denotes for year and $\mathrm{j}=1,2,3 \ldots, 12$ denotes for month. $\mathrm{P}_{\max , \mathrm{j}}$ and $\mathrm{P}_{\min , \mathrm{j}}$ are the maximum and minimum values of the precipitation for month $\mathrm{j}$, respectively. As described by the above equation, PCI values are calculated based on the group of maximum and minimum values for each grid cell, which are used to minimize the influences of seasonality to the results.

\subsubsection{Vegetation condition index (VCI)}

In order to analyze drought conditions over the South Asia region, NDVI data were downloaded from the NASA Land Processes Distributed Active Archive Center (LP DAAC; https://lpdaac.usgs.gov). The drought indicators were measured from the latest MOD13Q1_NDVI monthly composite products of the MODIS Terra satellites from 2003 to 2018 (Herrmann (Herrmann, Anyamba, \& Tucker, 2005). From the NDVI datasets, temporally and spatially aggregated vegetation condition index (VCI) were calculated. The VCI improves the annual variations of a vegetation index (e.g., NDVI) response to weather conditions variations, although lowering the effect of ecosystem specific responses that are determined by climate, soils, topography and type of the vegetation (Piao, Mohammat, Fang, Cai, \& Feng, 2006). We used Eq. (2) to calculate the vegetation condition index (VCI) (García-León, Contreras, \& Hunink, 2019)et al., 2019).

$$
\left.V C I=\frac{\left(N D V I \quad \mathrm{NDVI}_{\text {min }}\right.}{\mathrm{NDVI}_{\max } \mathrm{NDVI}_{\min }}\right) \times 100 \%
$$

Where NDVI is the NDVI time series on a specified time scale, and NDVI min and $\mathrm{NDVI}_{\text {max }}$ are the multi-year minimum and maximum values of the NDVI series, respectively.VCI is calculated on a grid cell-by-cell basis and can be applied to detect the impacts of abnormal weather conditions on vegetation. VCI is valuable for distinguishing the short-term weather signal from the long-term ecological signal and is a good index of water stress conditions relative to NDVI. According to Kogan (1995), VCI values of [?]35\% reflect drought conditions, while VCI values between $35 \%$ and $50 \%$ are regarded as normal or near normal conditions. VCI values of $50 \%$ or above are considered as favourable conditions.

The composite NDVI data for each month of the selected year was calculated for each grid cell. Then, the multi-year minimum and maximum NDVI values for each month period were derived from their corresponding records of the study period (2003-2018). Following Eq. (2), we produced the VCI series. The resulting 192 monthly images were used to create the drought maps on multiple time scales and to determine the relationship between monthly precipitation and vegetation status.

\subsubsection{Temperature condition index (TCI)}

Moderate Resolution Imaging Spectroradiometer (MODIS) for Land Surface Temperature (LST) product was used to study Temperature Condition Index (TCI). The MODIS Land Surface Temperature datasets were downloaded from https://lpdaac.usgs.gov/products/mod11c3v006. TCI was produced by employing LST 
(Land Surface Temperature) from MOD11C3 monthly LST with spatial resolution of $0.05^{\circ}$, and calculated using the below equation (Guo et al., 2018):

$$
T C I=\left(\frac{L S T \quad \mathrm{LST}_{\min }}{\mathrm{LST}_{\max } \mathrm{LST}_{\min }}\right) \times 100 \%
$$

where $\mathrm{LST}_{\mathrm{i}}, \mathrm{LST}_{\text {min }}$ and $\mathrm{LST}_{\max }$ are defined as LST of present month, minimum and maximum LST value in multi-year. TCI values range 0-100, as shown by different scholars, whereby low values of TCI indicate unfavorable conditions, while the high values of TCI indicate optimal conditions (Jiao et al., 2019; Zhang et al., 2017).

\subsubsection{Panel modelling}

A number of studies have investigated the relation between drought indices, area harvested, crop yield and production using different models, for instance (García-León et al., 2019; Tuvdendorj, Wu, Zeng, Batdelger, \& Nanzad, 2019; Zambrano, Vrieling, Nelson, Meroni, \& Tadesse, 2018). Our proposed model, which is consistent with the broader literature on the determinants of climate, that essentially states that drought indices are a function of weather impact on area harvested, crop yield and production, can be written in the following form:

$$
\mathrm{AH}, Y \text { orP }=f\left[\begin{array}{c}
\text { Precipitation condition index, temperature condition index, } \\
\text { vegetation condition index }
\end{array}\right]
$$

This essentially states that drought indices, which include PCI TCI and VCI, as shown in the above question our study is a panel data study, therefore Eq. (5) can be written in, the following form:

$$
X=\beta 0+\beta 1 \text { PCIt }+\beta 2 \text { TCIt }+\beta 2 \text { VCIt }+u t .
$$

And Eq. 5 can be written in panel data form as follows:

$$
X i, t=\beta 0+\beta 1 \mathrm{PCIi}, t+\beta 2 \mathrm{TCIi}, t+\beta 3 \mathrm{VCIi}, t+\varepsilon \iota, t
$$

Where, X refers to area harvested (ha), production (hg/ha) and yield (tons)

\subsubsection{Integrated Drought Severity Index (IDSI)}

Recently, scholars have used techniques such as Principal Component Analysis (PCA) to join VCI and TCI to obtain integrated drought characteristics for vegetation health status indication. However PCA has its constraint as it relies on size of data distribution and PCA is a result of two MODIS tiles and thus will not have access to continuity. In order to overcome these shortcomings, a new Integrated Drought Severity Index (IDSI) was developed depend upon the data combination technique which effectively determined the multi-resolution effect of VCI, TCI and PCI products. We calculated IDSI using the following formula:

$\mathrm{IDSI}_{\mathrm{ijk}}=\left[L * \mathrm{VCI}_{\mathrm{ijk}} *\left\langle 1+\frac{1}{\left(L\left(\mathrm{VCI}_{\mathrm{ijk}}+\mathrm{TCI}_{\mathrm{ijk}}+\mathrm{PCI}_{\mathrm{ijk}}+C\right)\right.} *\left(\mathrm{TCI}_{\mathrm{ijk}}+\mathrm{PCI}_{\mathrm{ijk}}\right)\right\rangle\right]$ 


\subsubsection{Economic losses}

Equation 8 reveals the correlation between yield anomaly and drought condition in all crops, the drought condition at year $\mathrm{t}$, which is the integrated drought severity index (IDSI). A linear regression analysis between the annual time series to determine the Pearson correlation coefficient $\mathrm{r}$ and the regression coefficientsintercept $a$ and slope $\beta$. We used the data in IDSI to categorize drought influences on yield.

$$
Y_{t}=a+\beta Z_{t}
$$

The drought-induced yield losses and economic losses for barley, maize, millet, rice and wheat from 2003 to 2017 were calculated as shown in the equation below:

$$
E=P \sum\left(A \sum_{t=1}^{n} x \frac{Y}{100}\right)
$$

Where

$\mathrm{E}=$ Economic loss $\$$

$\mathrm{P}=$ average producer price by crop [U.S. $\$ /$ ton, If $\mathrm{P}$ is unavailable for a target country, the average $\mathrm{P}$ value of the other neighboring country is substituted.

$\mathrm{A}=$ Harvested area (ha)

$\mathrm{Y}=$ Percentage drought-induced yield loss

$x=5$-yr centered moving average of crop yield tons/ha, which is expressed as the following:

$$
x=\frac{1}{5} \sum_{i-2}^{2} t+i
$$

The national-level drought-induced economic loss for the four target crops from 2003 to 2017 is computed applying the equation below:

$$
\mathrm{AGDP}=\left[\frac{\text { Value2Added agricultural percentage of GDP }}{100}\right] * 100
$$

Where the value-added agricultural percentage of GDP is the GDP share of the agricultural sector (\%). GDP $(\$)$ is gross domestic production.

\section{Results and discussion}

\subsection{Spatiotemporal characteristics of droughts in South Asia}

Drought indices such as PCI, TCI and VCI play a key role in the evaluation the influence of drought on agriculture and have been largely accepted in regional assessments (García-León (García-León et al., 2019; Zhao, Cong, He, Yang, \& Qin, 2017). The monthly values of PCI, TCI and VCI indicated that South Asia experiences drought conditions from January to June each year, while the months from July to December showed high values of PCI, TCI and VCI (Figure. 2). The VCI values significantly dropped from January to May, while for June to September, they gradually increased. Beyond September, there was a decrease in the indices' values up to December. The PCI trend revealed drought conditions which started in 2003 and lasted 
up to 2010. The lowest value of PCI was detected in 2006 at $28 \%$, the highest water stress in the South Asian region (Figure. 2). This had an impact on vegetation development, therefore the VCI correspondingly showed lower values at about $33 \%$, which was classified as severe drought conditions. The VCI is categorized as the most suitable index among the other examined indices to evaluate vegetation analysis and drought over south Asia. In fact, several investigations have applied VCI to examine vegetation characteristics and drought (Baniya, Tang, Xu, Haile, \& Chhipi-Shrestha, 2019; Qian et al., 2016) proved that the tendency of drought was increasing over the period 2003-2010 in South Asia. For example, Bhutan was experiencing extreme dry conditions in 2005 and 2006 (Tshewang, Morrison, \& Tobias, 2018). Also, Nepal underwent droughts according to Ali et al. (2019), who reported that the 2008-2009 drought in Nepal was the most extreme on record. The Nepalese Government's Department of Hydrology and Meteorology stated that the received lower than 50\% of average rainfall in 2008 and 2009 (Dahal et al., 2016).

It is obviously visible in the PCI, TCI and VCI maps that most of the precipitation is concentrated in the eastern regions of South Asia as presented in Figure. 2, and the northwest areas are relatively arid. The southern regions of South Asia indicated high temperatures, while the northeastern area had low temperatures. VCI maps generally indicated that the extent of the farming and pastoral land uses is located in the eastern region of south Asia, signified by the high VCI values recorded in the area. It is understandable that South Asia has a very little vegetation cover given it's extremely dry weather (Baniya et al., 2019). The results of the annual time scale presented that there was a 20 percent chance of severe drought occurring (VCI [?] 35\%).

\subsection{The integrated drought severity index (IDSI) and its relation with yield anomaly}

Generally, Bhutan had the lowest level of drought conditions during this period among the six countries, characterized by moderate to no drought conditions (Figure. 3). In contrast, Afghanistan, Pakistan and part of India had the driest conditions according to the IDSI. Nepal and the eastern part of India showed pre-drought IDSI values on the Spatiotemporal map (Figure. 3).

According to the characteristic drought values of IDSI and yield anomaly in Figure. 4, 2003 to 2011 were the driest years across all countries, with annual values ranging between -1 and -3 . These results indicate that South Asia region experienced repeated and extended droughts between 2003 and 2011. The rest of the years were characterized by normal drought conditions. The results of the IDSI and YAI concurred on the drought occurrence (Figure. 4), with a correlation coefficient larger than 0.85 in all of the countries $(\mathrm{P}<$ 0.001). These significant relationship prove that drought conditions managing crop production in this region. Also, the result shows that drought impact on crop production could be decreased by changing to waterdemanding crops. In most of South Asia, 2003 was the driest year, during which these areas experienced severe to extreme droughts, resulting in the lowest crop yield (Figure. 4).

Validation was carried out using IDSI anomaly and yield anomaly drought index. The results indicated that IDSI and yield anomaly are highly correlated (Figure. 4), and all of them passed the significant test (p-value < 0.01). This proves the potential of the new drought index (IDSI), to monitor regional drought conditions using remote sensing data. This evaluation proved that IDSI not only reflects the water deficit in meteorological drought but also reflects the drought influence on agriculture and it can be used to comprehensively monitor and evaluate drought.

The results of the panel model in Table 1 showed that drought indices PCI, and TCI have positive and statistically significant effects $(\mathrm{P}<0.01)$ on area harvested, production and yield of barley, millet, Maize and wheat (Table. 1 and 2). As reported by Borgomeo et al. (2018), higher minimum temperatures during the growing season results in high yields while high rainfall excess in the latter stages of the crop (maturity and harvest) can adversely affect the yield. Also, the Table 1 shows that the VCI has a significant effect on barley and rice $(\mathrm{P}<0.01)$. However, VCI does not have significant impact on harvested area $0.50,0.21$, 0.34, 0.23 and 0.21 of Barley, Millet, Maize, Rice and wheat respectively (Table. 1 and 2). 
The panel model showed that drought indices have a positive effect on the yield of the crops considered in this study. Kuwayama, Thompson, Bernknopf, Zaitchik, and Vail (2018) et al. (2018) found statistically significant effects of drought on crop yields in the US.

\subsection{Drought induced economic loss}

The results showed that between 2003 and 2017, South Asia incurred massive economic losses for the five crops considered in this study to a tune of about $\$ 10316$ billion for wheat, $\$ 1116$ billion for rice, $\$ 493$ billion for millet, $\$ 910$ billion for maize and $\$ 93$ billion for barley (Figure 5). The huge losses attributed to wheat during the study were distributed as follows: Afghanistan $\$ 162$ billion, Pakistan $\$ 578$ billion, India $\$ 312$ billion, Bhutan $\$ 116$ billion, Nepal $\$ 645$ billion and Bangladesh $\$ 241$ billion (Figure 5). These losses could have resulted from increasing temperatures in the region. C. Zhao et al. (2017) proved that temperature increase resulted in reduced global yields of wheat. Also the insufficient rainfall recorded during 2008 - 2010 especially in the northern regions of Afghanistan induced substantial disaster on the rain fed crops in six regions. Droughts lead to substantial economic loss along with social and environmental influences, which might be significantly affecting the human systems in the country. Many activities of agricultural economics in Afghanistan depend basically on rainfall. When drought occurs, the agricultural sector is generally the most impacted as a consequence of its dependence on rainfall and soil moisture (Savage, Dougherty, Hamza, Butterfield, \& Bharwani, 2009). For example, it was observed that a $20 \%$ drop in rice production was experienced during the exceptionally dry seasons in the several years spanning 2003 to 2017, of which droughts are forecasted to increase in the future.

In China (S. Zhao et al., 2017) demonstrated that wheat production rates would be reduced by 3 to $10 \%$ due to a $1 \operatorname{deg} \mathrm{C}$ increase in temperature during the growing period. The study also reported that the increase in temperature over the last two decades would have resulted in crop yields dropping by $4.5 \%$, if not for the increased use of resources like irrigation and application of fertilizer. Variations in temperature and precipitation improved wheat yield in northern China by 0.9-12.9\%. Eruygur and Ozokcu (2016) confirmed that if temperature increased within the earth's surface the soil would turn out to be drier ultimately causing decrease yields.

The agriculture losses in South Asia have habitually grown as a result of increasingly severe droughts. The results of the national-level drought-induced economic loss for the four target crops from 2003 to 2017 showed that AGDP has a statistically significant correlation ( $\mathrm{p}$-value $<0.01$ ) with economic loss and the correlation coefficient $\mathrm{R}^{2}$ registered 0.32, 0.82, 0.84, 0.510 .79 and 0.81 in Afghanistan, Pakistan, India, Bhutan, Nepal and Bangladesh respectively (Figure 6). This implies that the prevalence of innovative agricultural technologies, for instance irrigation systems, breeding, and crop control, in developed countries tends to decrease drought-induced yield losses. Regarding the predicted boosts in per capita GDP in the foreseeable future, this process will likely be followed by investments in agricultural research and apply the new technical packages in developing countries. In particular, the increase in areas using irrigation for cultivation of crops will be initialized and then increased drought resilience might be anticipated to all crops. Enhanced drought management will lead to growth in farm incomes of small household farmers and also improve food security in drought effected areas globally.

\section{Conclusion}

In this study, we provide a detailed analysis of drought occurrence in South Asia using different drought indices for the period 2003 to 2018. The remote sensing and crop yield based indices reveal that South Asia has experienced region-wide droughts from 2003 to 2011, which has massively affected area harvested, production and yield in this region. The damage that resulted from drought occurrence was calculated as a percentage of agricultural gross domestic production (AGDP) and this can be used by both international and national-level policy makers to allocate resources towards building resilience and the protection against 
severe drought events. The study showed drought condition caused economic losses and revealed countrylevel economic losses in production of crop. The exhibited relation between AGDP and economic crop loss in south Asia provides scientific support for decision making, targeted disaster mitigation and adaptation.

This study will assist to better understand the spatial and temporal distribution of crop-specific droughtrelated damage. Therefore, this study will help and provide policymakers in national governments and international organizations who desire to identify regions in which drought risk management and control should be pondered.

References

Agrawala, S., Barlow, M., Cullen, H., \& Lyon, B. J. I. R. I. f. C. P., Palisades. (2001). The drought and humanitarian crisis in Central and Southwest Asia: a climate perspective, IRI special report N. 01-11. 24.

Ahmadi, B., Ahmadalipour, A., Tootle, G., \& Moradkhani, H. (2019). Remote Sensing of Water Use Efficiency and Terrestrial Drought Recovery across the Contiguous United States. Remote Sensing, 11(6). doi:10.3390/rs11060731

Ali, S., Henchiri, M., Yao, F., \& Zhang, J. (2019). Analysis of vegetation dynamics, drought in relation with climate over South Asia from 1990 to 2011. Environmental Science and Pollution Research, 26(11), 11470-11481. doi:10.1007/s11356-019-04512-8

Anderson, M. C., Zolin, C. A., Sentelhas, P. C., Hain, C. R., Semmens, K., Tugrul Yilmaz, M., . . Tetrault, R. (2016). The Evaporative Stress Index as an indicator of agricultural drought in Brazil: An assessment based on crop yield impacts. Remote Sensing of Environment, 174, 82-99. doi:https://doi.org/10.1016/j.rse.2015.11.034

Asim, M., \& Nawaz, Y. (2018). Child Malnutrition in Pakistan: Evidence from Literature. Children (Basel, Switzerland), 5(5), 60. doi:10.3390/children5050060

Baniya, B., Tang, Q., Xu, X., Haile, G. G., \& Chhipi-Shrestha, G. (2019). Spatial and Temporal Variation of Drought Based on Satellite Derived Vegetation Condition Index in Nepal from 1982-2015. Sensors (Basel, Switzerland), 19(2), 430. doi:10.3390/s19020430

Bayissa, Y. A., Tadesse, T., Svoboda, M., Wardlow, B., Poulsen, C., Swigart, J., \& Van Andel, S. J. (2019). Developing a satellite-based combined drought indicator to monitor agricultural drought: a case study for Ethiopia. GIScience \& Remote Sensing, 56(5), 718-748. doi:10.1080/15481603.2018.1552508

Borgomeo, E., Vadheim, B., Woldeyes, F. B., Alamirew, T., Tamru, S., Charles, K. J., . . . Walker, O. (2018). The Distributional and Multi-Sectoral Impacts of Rainfall Shocks: Evidence From Computable General Equilibrium Modelling for the Awash Basin, Ethiopia. Ecological Economics, 146, 621-632. doi:https://doi.org/10.1016/j.ecolecon.2017.11.038

Carrão, H., Naumann, G., \& Barbosa, P. (2016). Mapping global patterns of drought risk: An empirical framework based on sub-national estimates of hazard, exposure and vulnerability. Global Environmental Change, 39, 108-124. doi:https://doi.org/10.1016/j.gloenvcha.2016.04.012

Cenacchi, N. (2014). Drought risk reduction in agriculture: A review of adaptive strategies in East Africa and the Indo-Gangetic plain of South Asia (Vol. 1372): Intl Food Policy Res Inst.

Clark, H., \& Wu, H. (2016). The sustainable development goals: 17 goals to transform our world.

Dizon, F. J. F., Josephson, A. L., \& Raju, D. (2019). The Nutrition Sensitivity of Food and Agriculture in South Asia: The World Bank.

Eruygur, O., \& Özokcu, S. J. E. Y. (2016). Impacts of climate change on wheat yield in Turkey: A heterogeneous panel study. 27, 219-255. 
FAO, R. U. h. w. f. o. a.-i. p. (2017). WFP, WHO (2017) The state of food security and nutrition in the world 2017.

Formetta, G., \& Feyen, L. (2019). Empirical evidence of declining global vulnerability to climate-related hazards. Global Environmental Change, 57, 101920. doi:https://doi.org/10.1016/j.gloenvcha.2019.05.004

Gao, S., Liu, R., Zhou, T., Fang, W., Yi, C., Lu, R., . . Luo, H. (2018). Dynamic responses of tree-ring growth to multiple dimensions of drought. 24(11), 5380-5390. doi:10.1111/gcb.14367

García-León, D., Contreras, S., \& Hunink, J. (2019). Comparison of meteorological and satellite-based drought indices as yield predictors of Spanish cereals. Agricultural Water Management, 213, 388-396. doi:https://doi.org/10.1016/j.agwat.2018.10.030

Giannini, A., Biasutti, M., \& Verstraete, M. M. (2008). A climate model-based review of drought in the Sahel: Desertification, the re-greening and climate change. Global and Planetary Change, 64(3), 119-128. doi:https://doi.org/10.1016/j.gloplacha.2008.05.004

Gouveia, C. M., Trigo, R. M., Beguería, S., \& Vicente-Serrano, S. M. (2017). Drought impacts on vegetation activity in the Mediterranean region: An assessment using remote sensing data and multi-scale drought indicators. Global and Planetary Change, 151, 15-27. doi:https://doi.org/10.1016/j.gloplacha.2016.06.011

Guo, H., Bao, A., Ndayisaba, F., Liu, T., Jiapaer, G., El-Tantawi, A. M., \& De Maeyer, P. (2018). Space-time characterization of drought events and their impacts on vegetation in Central Asia. Journal of Hydrology, 564, 1165-1178. doi:https://doi.org/10.1016/j.jhydrol.2018.07.081

Hagenlocher, M., Meza, I., Anderson, C. C., Min, A., Renaud, F. G., Walz, Y., . . S Sebesvari, Z. (2019). Drought vulnerability and risk assessments: state of the art, persistent gaps, and research agenda. Environmental Research Letters, 14(8), 083002. doi:10.1088/1748-9326/ab225d

Herrmann, S. M., Anyamba, A., \& Tucker, C. J. (2005). Recent trends in vegetation dynamics in the African Sahel and their relationship to climate. Global Environmental Change, 15(4), 394-404. doi:https://doi.org/10.1016/j.gloenvcha.2005.08.004

Jiao, W., Wang, L., Novick, K. A., \& Chang, Q. (2019). A new station-enabled multisensor integrated index for drought monitoring. Journal of Hydrology, 574, 169-180. doi:https://doi.org/10.1016/j.jhydrol.2019.04.037

Kellogg, W. W. (2019). Climate change and society: consequences of increasing atmospheric carbon dioxide: Routledge.

Kim, W., Iizumi, T., \& Nishimori, M. (2019). Global Patterns of Crop Production Losses Associated with Droughts from 1983 to 2009. Journal of Applied Meteorology and Climatology, 58(6), 1233-1244. doi:10.1175/JAMC-D-18-0174.1

Klönne, U. J. S. t. s. I. (2012). Drought in the Sahel: global and local driving forces and their impact on vegetation in the 20 th and 21 st century.

Kogan, F. N. (1995). Application of vegetation index and brightness temperature for drought detection. Advances in Space Research, 15(11), 91-100. doi:https://doi.org/10.1016/0273-1177(95)00079-T

Kotharkar, R., Ramesh, A., \& Bagade, A. (2018). Urban Heat Island studies in South Asia: A critical review. Urban Climate, 24, 1011-1026. doi:https://doi.org/10.1016/j.uclim.2017.12.006

Kuwayama, Y., Thompson, A., Bernknopf, R., Zaitchik, B., \& Vail, P. (2018). Estimating the Impact of Drought on Agriculture Using the U.S. Drought Monitor. American Journal of Agricultural Economics, 101(1), 193-210. doi:10.1093/ajae/aay037 \%J American Journal of Agricultural Economics

Lesk, C., Rowhani, P., \& Ramankutty, N. (2016). Influence of extreme weather disasters on global crop production. Nature, 529, 84. doi:10.1038/nature16467 
https://www.nature.com/articles/nature16467\#supplementary-information

Liu, L., Gudmundsson, L., Hauser, M., Qin, D., Li, S., \& Seneviratne, S. I. (2019). Revisiting assessments of ecosystem drought recovery. Environmental Research Letters, 14(11), 114028. doi:10.1088/1748-9326/ab4c61

Matewos, T. (2019). Deconstructing institutional roles in climate change adaptation: The case of local public institutions in drought-prone districts of Sidama, Southern Ethiopia. Environmental Science \& Policy, 98, 47-53. doi:https://doi.org/10.1016/j.envsci.2019.05.005

McDowell, N. G., Michaletz, S. T., Bennett, K. E., Solander, K. C., Xu, C., Maxwell, R. M., \& Middleton, R. S. (2018). Predicting Chronic Climate-Driven Disturbances and Their Mitigation. Trends in Ecology \& Evolution, 33(1), 15-27. doi:https://doi.org/10.1016/j.tree.2017.10.002

Mohmmed, A., Zhang, K., Kabenge, M., Keesstra, S., Cerdà, A., Reuben, M., . . Ali, A. A. S. (2018). Analysis of drought and vulnerability in the North Darfur region of Sudan. 29(12), 4424-4438. doi:10.1002/ldr.3180

NOURELDEEn, N., Kebiao, M., MOHMMED, A., Zijin, Y., \& Yanying, Y. J. J. o. M. R. (2020). SpatioTemporal Drought Assessment over Sahelian Countries from 1985 To 2015. 34, 1-15.

Paciorek, C. J., Stevens, G. A., Finucane, M. M., Ezzati, M., \& Nutrition Impact Model Study, G. (2013). Children's height and weight in rural and urban populations in low-income and middle-income countries: a systematic analysis of population-representative data. The Lancet. Global health, 1(5), e300-e309. doi:10.1016/S2214-109X(13)70109-8

Parsons, D. J., Rey, D., Tanguy, M., \& Holman, I. P. (2019). Regional variations in the link between drought indices and reported agricultural impacts of drought. Agricultural Systems, 173, 119-129. doi:https://doi.org/10.1016/j.agsy.2019.02.015

Piao, S., Mohammat, A., Fang, J., Cai, Q., \& Feng, J. (2006). NDVI-based increase in growth of temperate grasslands and its responses to climate changes in China. Global Environmental Change, 16(4), 340-348. doi:https://doi.org/10.1016/j.gloenvcha.2006.02.002

Qian, X., Liang, L., Shen, Q., Sun, Q., Zhang, L., Liu, Z., . . Qin, Z. (2016). Drought trends based on the VCI and its correlation with climate factors in the agricultural areas of China from 1982 to 2010. Environmental Monitoring and Assessment, 188(11), 639. doi:10.1007/s10661-016-5657-9

Rajsekhar, D., Singh, V. P., \& Mishra, A. K. (2015). Multivariate drought index: An information theory based approach for integrated drought assessment. Journal of Hydrology, 526, 164-182. doi:https://doi.org/10.1016/j.jhydrol.2014.11.031

Renard, D., \& Tilman, D. (2019). National food production stabilized by crop diversity. Nature, 571(7764), 257-260. doi:10.1038/s41586-019-1316-y

Sánchez, N., González-Zamora, Á., Martínez-Fernández, J., Piles, M., \& Pablos, M. (2018). Integrated remote sensing approach to global agricultural drought monitoring. Agricultural and Forest Meteorology, 259, 141153. doi:https://doi.org/10.1016/j.agrformet.2018.04.022

Savage, M., Dougherty, B., Hamza, M., Butterfield, R., \& Bharwani, S. J. S. E. I. O., UK. (2009). Socioeconomic impacts of climate change in Afghanistan.

Seidl, R., Thom, D., Kautz, M., Martin-Benito, D., Peltoniemi, M., Vacchiano, G., . . Reyer, C. P. O. (2017). Forest disturbances under climate change. Nature Climate Change, 7, 395. doi:10.1038/nclimate3303 https://www.nature.com/articles/nclimate3303\#supplementary-information

Stagge, J. H., Kohn, I., Tallaksen, L. M., \& Stahl, K. (2015). Modeling drought impact occurrence based on meteorological drought indices in Europe. Journal of Hydrology, 530, 37-50. doi:https://doi.org/10.1016/j.jhydrol.2015.09.039 
Tshewang, U., Morrison, J. G., \& Tobias, M. C. (2018). Bionomics in the Dragon Kingdom: Ecology, Economics and Ethics in Bhutan: Springer.

Tuvdendorj, B., Wu, B., Zeng, H., Batdelger, G., \& Nanzad, L. (2019). Determination of Appropriate Remote Sensing Indices for Spring Wheat Yield Estimation in Mongolia. Remote Sensing, 11(21). doi:10.3390/rs11212568

Vicente-Serrano, S. M., Beguería, S., \& López-Moreno, J. I. (2009). A Multiscalar Drought Index Sensitive to Global Warming: The Standardized Precipitation Evapotranspiration Index. Journal of Climate, 23(7), 1696-1718. doi:10.1175/2009JCLI2909.1

Zambrano, F., Vrieling, A., Nelson, A., Meroni, M., \& Tadesse, T. (2018). Prediction of drought-induced reduction of agricultural productivity in Chile from MODIS, rainfall estimates, and climate oscillation indices. Remote Sensing of Environment, 219, 15-30. doi:https://doi.org/10.1016/j.rse.2018.10.006

Zhang, L., Jiao, W., Zhang, H., Huang, C., \& Tong, Q. (2017). Studying drought phenomena in the Continental United States in 2011 and 2012 using various drought indices. Remote Sensing of Environment, 190, 96-106. doi:https://doi.org/10.1016/j.rse.2016.12.010

Zhao, C., Liu, B., Piao, S., Wang, X., Lobell, D. B., Huang, Y., . . A Asseng, S. (2017). Temperature increase reduces global yields of major crops in four independent estimates. Proceedings of the National Academy of Sciences, 114(35), 9326. doi:10.1073/pnas.1701762114

Zhao, S., Cong, D., He, K., Yang, H., \& Qin, Z. (2017). Spatial-Temporal Variation of Drought in China from 1982 to 2010 Based on a modified Temperature Vegetation Drought Index (mTVDI). Scientific reports, 7(1), 17473-17473. doi:10.1038/s41598-017-17810-3

Table 1. The result of the panel model of area harvested, production yield (Barley, millet, maize and rice) and drought indices.

\begin{tabular}{|c|c|c|c|c|c|c|c|c|}
\hline & & & Barley & & & & & \\
\hline \multirow{6}{*}{ Area harvested (ha) } & & Estimate & Std. Error & t-value & $\operatorname{Pr}(>|\mathrm{t}|)$ & \multirow{6}{*}{ Area harvested (ha) } & & \\
\hline & (Intercept) & 75059.6 & 427681.6 & 0.1755 & 0.86 & & (Intercept) & \\
\hline & PCI & -23484.6 & $5990.9-3$. & 9200 & $0.00 * * *$ & & PCI & \\
\hline & TCI & 21686.1 & 4001.4 & 5.4196 & $0.00 * * *$ & & TCI & \\
\hline & VCI & -5195.3 & $8109.4-0$ & 6407 & 0.50 & & VCI & \\
\hline & & Estimate & Std. Error & t-value & $\operatorname{Pr}(>|\mathrm{t}|)$ & & & \\
\hline \multirow{5}{*}{ Production (hg/ha) } & (Intercept) & -1003452 & 985141 & -1.0186 & 0.31 & \multirow{5}{*}{ Production (hg/ha) } & (Intercept) & \\
\hline & PCI & -51099 & 13800 & -3.7029 & $0.00 * * *$ & & PCI & \\
\hline & TCI & 56149 & 9217 & 6.0919 & $0.00 * * *$ & & TCI & \\
\hline & $\mathrm{VCI}$ & 3438 & 18680 & 0.1841 & 0.89 & & VCI & \\
\hline & & Estimate & Std. Error & t-value & $\operatorname{Pr}(>|t|)$ & & & \\
\hline \multirow{5}{*}{ Yield (tonnes) } & (Intercept) & 8388.49 & 10253.25 & -0.8181 & 0.42 & \multirow{5}{*}{ Yield (tonnes) } & (Intercept) & \\
\hline & PCI & -628.81 & 143.63 & -4.3781 & $0.00 * * *$ & & PCI & \\
\hline & TCI & 356.36 & 95.93 & 3.7148 & $0.00^{* * *}$ & & TCI & \\
\hline & $\mathrm{VCI}$ & 496.67 & 194.42 & 2.55470 & $.012 *$ & & $\mathrm{VCI}$ & \\
\hline & & & Maize & & & & & \\
\hline \multirow{7}{*}{ Area harvested (ha) } & & Estimate & Std. Error & t-value & $\operatorname{Pr}(>|t|)$ & \multirow{7}{*}{ Area harvested (ha) } & & \\
\hline & (Intercept) & -12255106 & 5062320 & -2.4208 & $0.02 *$ & & (Intercept) & \\
\hline & PCI & -274481 & 70912 & -3.8707 & $0.00 * * *$ & & PCI & \\
\hline & TCI & 372982 & 47363 & 7.8749 & $0.00 * * *$ & & TCI & \\
\hline & $\mathrm{VCI}$ & 92265 & 95989 & 0.9612 & 0.34 & & $\mathrm{VCI}$ & \\
\hline & & Estimate & Std. Error & t-value & $\operatorname{Pr}(>|t|)$ & & & \\
\hline & (Intercept) & -27677089 & 12491611 & -2.2157 & $0.03 *$ & & (Intercept) & \\
\hline
\end{tabular}




\begin{tabular}{|c|c|c|c|c|c|c|c|c|}
\hline & & & Barley & & & & & \\
\hline \multirow{5}{*}{ Production (hg/ha) } & PCI & -646207 & 174981 & -3.693 & $0.00 * * *$ & \multirow{4}{*}{ Production (hg/ha) } & PCI & \\
\hline & TCI & 899386 & 116872 & 7.6955 & $0.00 * * *$ & & TCI & \\
\hline & VCI & 179960 & 236858 & 0.7598 & 0.45 & & VCI & \\
\hline & & Estimate & Std. Error & $\mathrm{t}$-value & $\operatorname{Pr}(>|t|)$ & & & \\
\hline & (Intercept) & -43266.788 & 32164.766 & -1.3452 & 0.18 & \multirow{4}{*}{ Yield (tonnes) } & (Intercept) & \\
\hline \multirow{3}{*}{ Yield (tonnes) } & PCI & 1878.204 & 450.56 & 4.1686 & $0.00 * * *$ & & PCI & \\
\hline & TCI & 44.097 & 300.9348 & 0.1465 & 0.88 & & TCI & \\
\hline & VCI & 372.302 & 609.888 & 0.6104 & 0.54 & & $\mathrm{VCI}$ & \\
\hline
\end{tabular}

Table 2. The result of the panel model of area harvested, production yield (Wheat) and drought indices.

\begin{tabular}{llllll}
\hline & & \multicolumn{3}{l}{ Wheat } \\
\hline & & Estimate & Std. Error & t-value & $\operatorname{Pr}(>|\mathrm{t}|)$ \\
& (Intercept) & -18394093 & 7097017 & -2.5918 & $0.01^{*}$ \\
Area harvested (ha) & PCI & -343285 & 99414 & -3.4531 & $0.00^{* * *}$ \\
& TCI & 469172 & 66400 & 7.0659 & $0.00 * * *$ \\
& VCI & 170423 & 134569 & 1.2664 & 0.21 \\
& & Estimate & Std. Error & t-value & $\operatorname{Pr}(>|\mathrm{t}|)$ \\
& (Intercept) & -20690895 & 7489259 & -2.7627 & $0.00 * *$ \\
Production (hg/ha) & PCI & -359003 & 104909 & -3.4221 & $0.00 * * *$ \\
& TCI & 505967 & 70070 & 7.2209 & $0.00^{* * *}$ \\
& VCI & 193273 & 142007 & 1.361 & 0.18 \\
& & Estimate & Std. Error & t-value & $\operatorname{Pr}(>|\mathrm{t}|)$ \\
Yield (Tonnes) & (Intercept) & -43266.788 & 32164.766 & -1.3452 & 0.18 \\
& PCI & 1878.204 & 450.56 & 4.1686 & $0.00 * * *$ \\
& TCI & 44.097 & 300.934 & 0.1465 & 0.88 \\
& VCI & 372.302 & 609.888 & 0.6104 & 0.54 \\
\hline
\end{tabular}



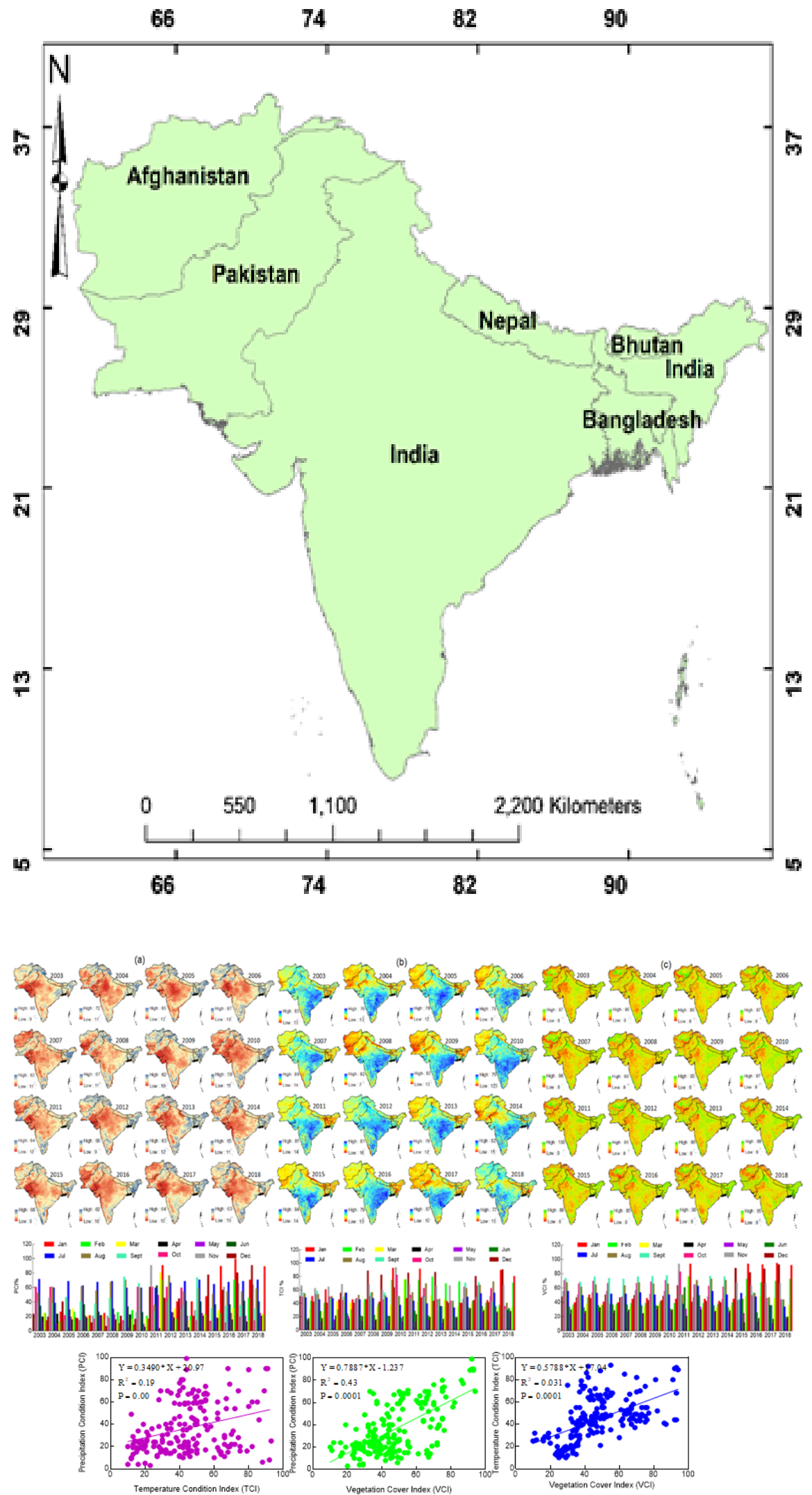


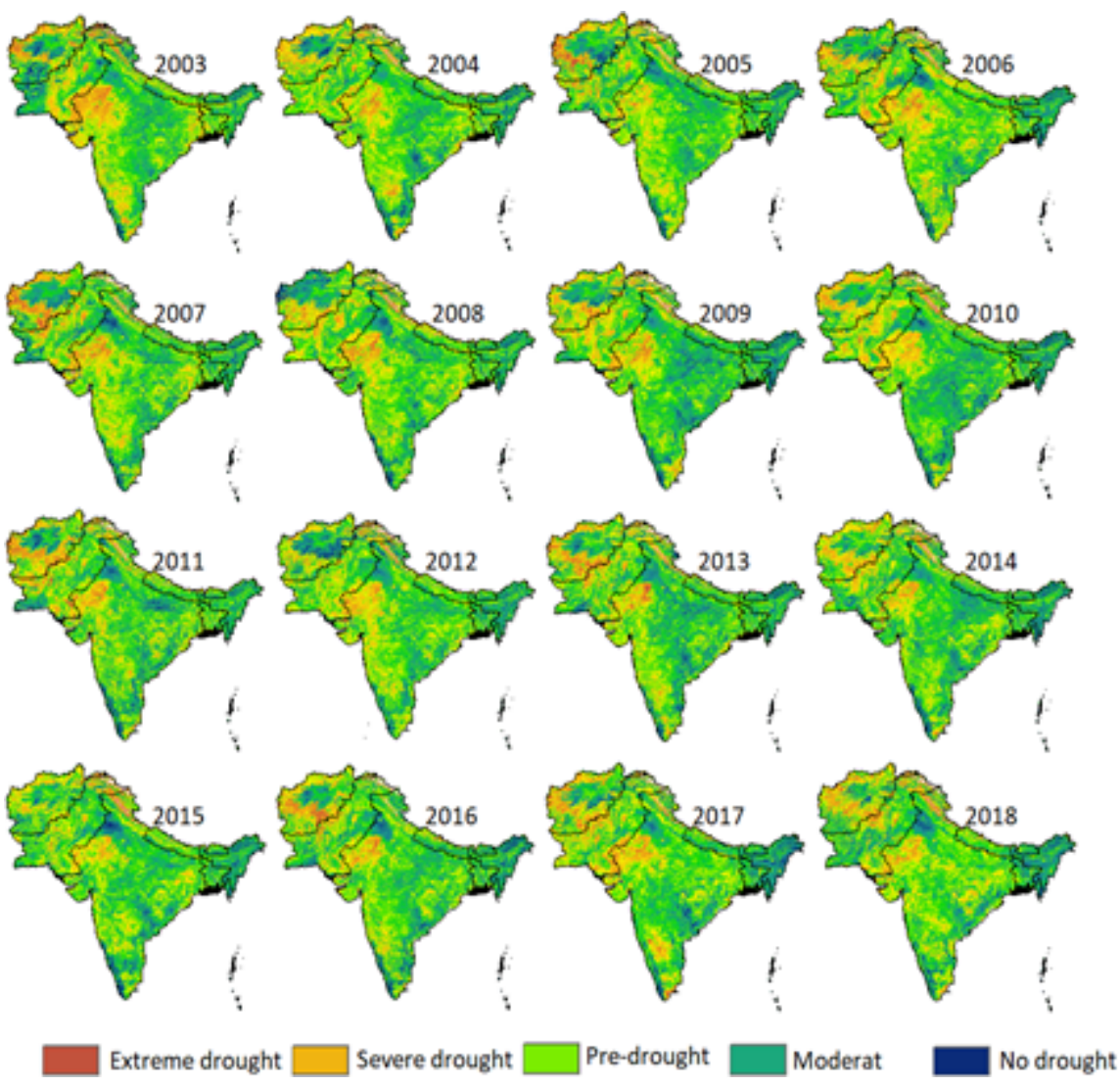



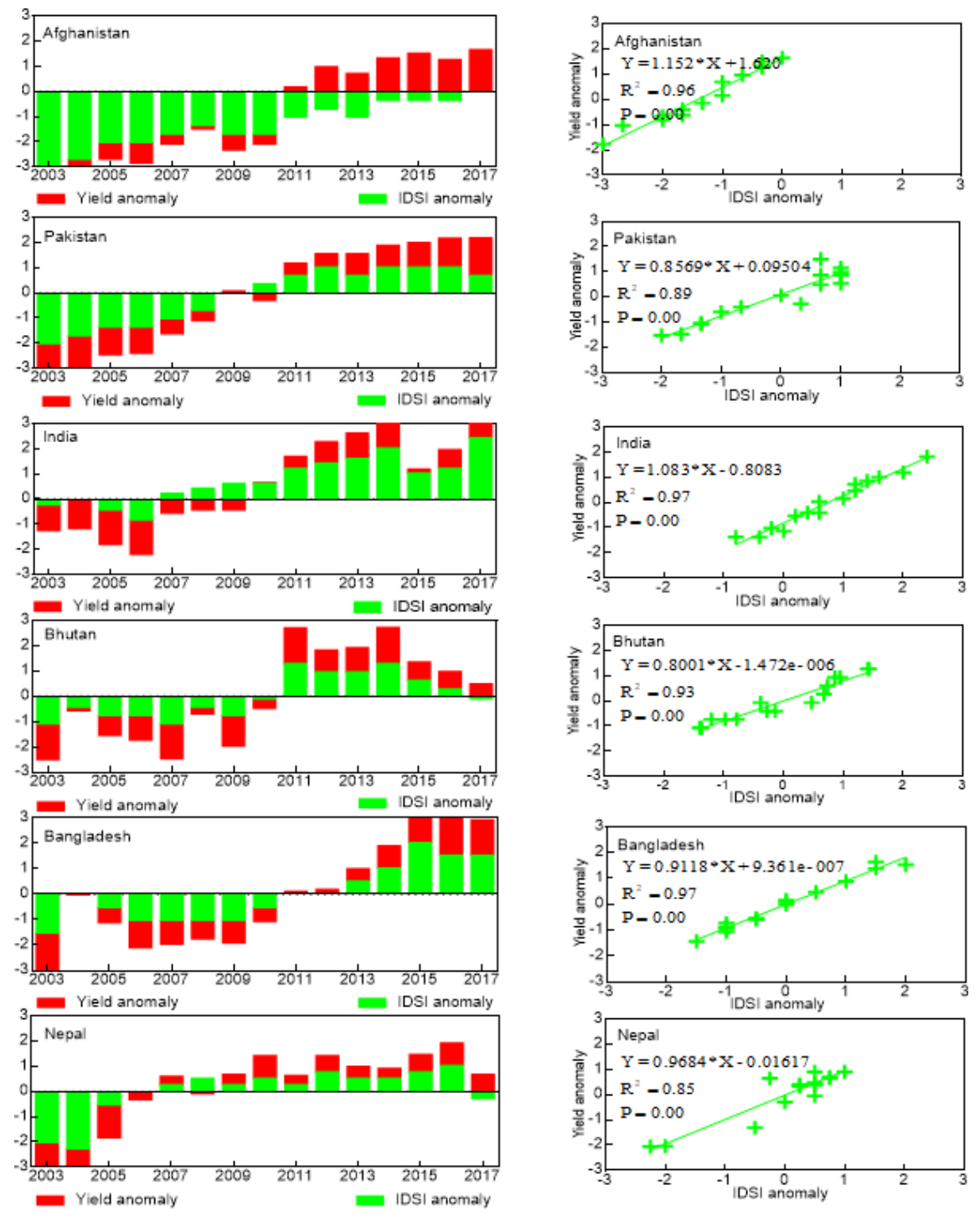

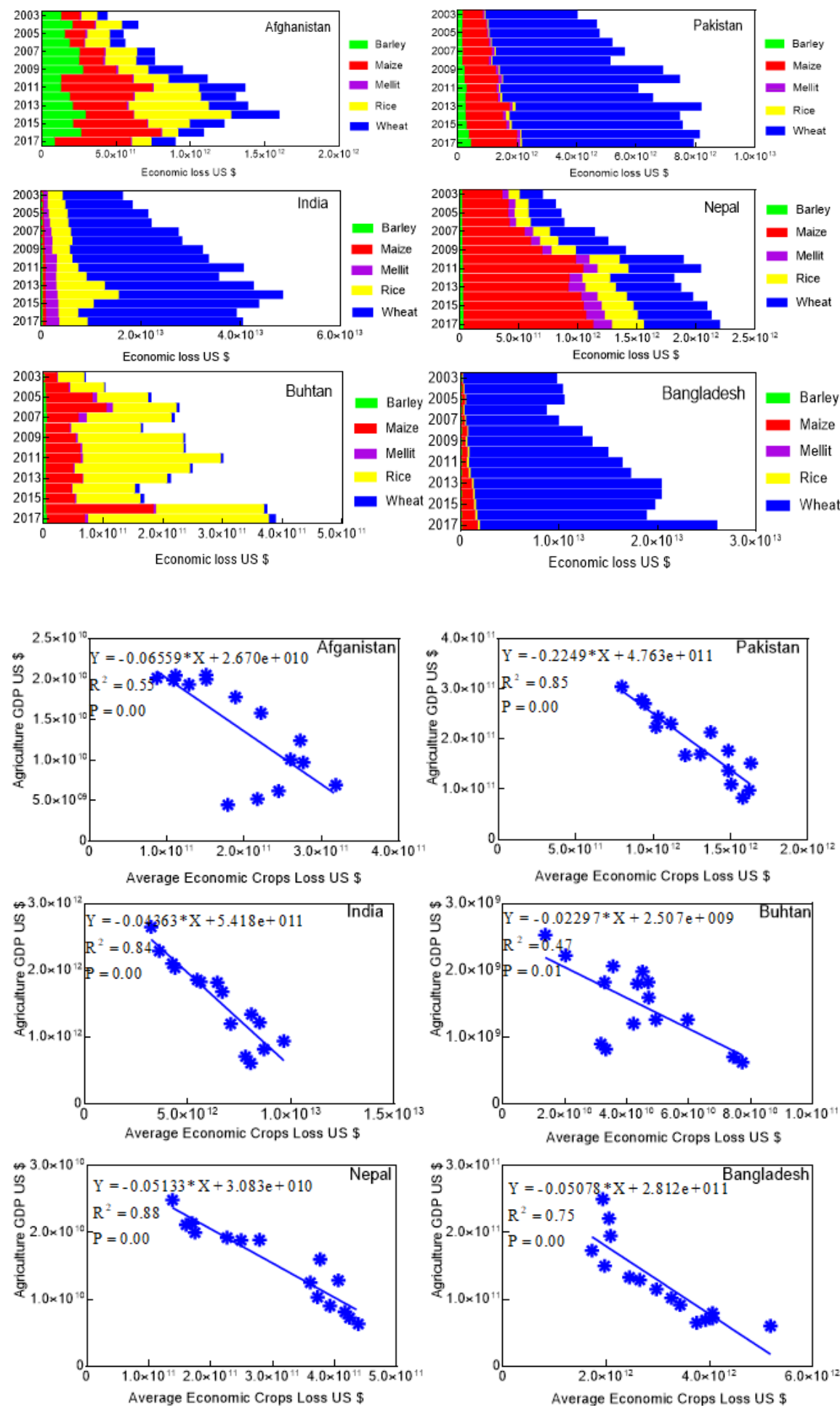